\title{
Activity Study of Self-Assembled Proteins on Nanoscale Diblock Copolymer Templates
}

\author{
Nitin Kumar, Omkar Parajuli, Adam Dorfman, Dylan Kipp and Jong-in Hahm*
}

Department of Chemical Engineering, The Pennsylvania State University, 160 Fenske Laboratory, University Park, Pennsylvania 16802. 


\section{Supporting Information}

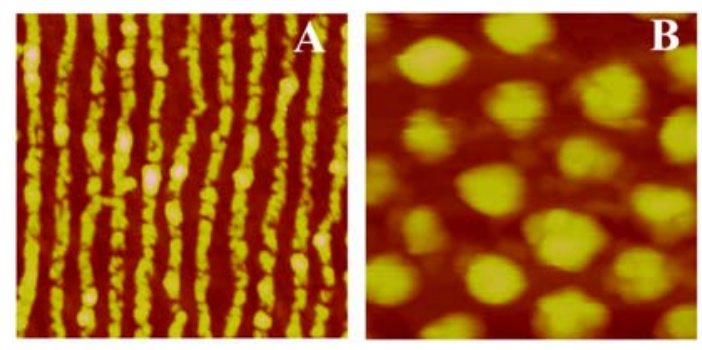

AFM images of immunoglobulin G (IgG) protein molecules on ordered polymeric microdomain templates at a monolayer forming coverage.

A. $500 \times 500 \mathrm{~nm}$ topography image of IgG assembled on asymmetric, aligned, lying-down, polystyrene-block-polymethylmethacrylate templates

B. $170 \times 170 \mathrm{~nm}$ topography image of IgG molecules adsorbed on hexagonally assembled polystyrene- $b$-polyvinylpyridine templates 